\title{
Satisfação e Apego ao Lugar: implicações para qualidade de vida em uma visão de marketing de lugares
}

\section{Place Satisfaction and Place Attachment: quality of life implications for place marketing}

\section{Satisfacción y Apego al Lugar : implicaciones para la calidad de vida bajo una visión de marketing de lugares}

Fabiana Gama de Medeiros ${ }^{1}$

Francisco José da Costa ${ }^{2}$

\begin{abstract}
Resumo
Esse estudo busca compreender a relação entre a satisfação ao lugar, o apego ao lugar e a qualidade de vida percebida pelos residentes de um lugar. A análise preliminar dos estudos realizados mostrou que o foco de marketing de lugares tem sido predominantemente voltado para aplicar as ferramentas tradicionais de marketing aos lugares, na busca de atrair visitantes, investidores e novos residentes, com menor ênfase aos agentes residentes dos lugares. Isto justificou o foco deste estudo nos residentes. A partir da revisão da literatura, foi proposto um modelo de relações entre os construtos, testado empiricamente através de modelagem de equações estruturais em amostras de residentes das cidades de João Pessoa, Campina Grande, Guarabira e suas cidades circunvizinhas, no estado da Paraíba. Além do modelo, também testamos e propomos uma escala para medir o construto satisfação com o lugar. Os resultados confirmam as hipóteses e apresentam a satisfação com o lugar e o apego ao lugar como preditores do construto qualidade de vida percebida; uma escala de satisfação com o lugar foi desenvolvida e proposta; e foram identificados os fatores específicos de um lugar que contribuem para a satisfação geral com o lugar.
\end{abstract}

Palavras-chave: Marketing de lugares; Residentes; Qualidade de vida.

\begin{abstract}
This study aims to understand the relationship between resident's place satisfaction, place attachment and perceived quality of life. Preliminary analysis of previous studies has demonstrated that focus of place marketing has lied predominantly on applying traditional marketing tools to places, seeking to attract visitors, investors and new residents, with little emphasis on residents. This justifies our focus on residents. From a literature review, we propose a model of relationships between the constructs, empirically tested using structural equation modeling on a sample of residents from the cities of João Pessoa, Campina Grande,

\footnotetext{
1 Professora de Administração da Universidade Federal da Paraíba. Doutoranda em Administração da Universidade Federal da Paraíba. João Pessoa-PA, Brasil. E-mail: gmfabiana@ hotmail.com

2 Professor do Programa de Pós-Graduação em Administração PPGA da Universidade Federal da Paraíba UFPB. Doutorando em Administração pela Fundação Getúlio Vargas. João Pessoa-PA, Brasil. E-mail: franzecosta@gmail.com
} 
Guarabira, and its surrounding cities, in the state of Paraiba. Along with proposing a model, we have also tested and proposed a scale to measure place satisfaction. Hypothesis were confirmed, presenting place satisfaction and place attachment as predictors of perceived quality of life; a place satisfaction scale was developed and proposed; and specific factors contributing to overall place satisfaction were identified.

Keywords: Place marketing ; Residents; Quality of life.

\section{Resumen}

Este estudio tiene como objetivo comprender la relación entre la satisfacción con el lugar, el apego al lugar y la calidad de vida percibida por los residentes de un lugar. El análisis preliminar de los estudios mostró que el enfoque de marketing de lugares se ha centrado principalmente en la aplicación de herramientas de marketing tradicionales a lugares, tratando de atraer a los visitantes, inversores y nuevos residentes, con menos énfasis en los agentes residentes de los lugares. Esto justifique el enfoque de este estudio sobre los residentes. A partir de la revisión de la literatura, hemos propuesto un modelo de relaciones entre los constructos, probadas empíricamente a través de modelos de ecuaciones estructurales en muestras de los habitantes de las ciudades brasileñas de João Pessoa, Campina Grande, Guarabira y sus ciudades circundantes en el estado de Paraíba. Además del modelo, también probamos y proponemos una escala para medir el constructo satisfacción con el lugar. Los resultados confirman las hipótesis y presentan la satisfacción con el lugar y el apego al lugar como predictores del constructo calidad de vida percibida; una escala de satisfacción con el lugar fue desarollada y propuesta; y fueran identificados los factores específicos de un lugar que contribuyen a la satisfacción general con el lugar.

Palabra-clave: Marketing de lugares; Residentes; Calidad de vida.

\section{Introdução}

Os estudos de marketing vêm avançando de forma acelerada rumo a uma orientação ao interesse social, conforme atesta a definição proposta pela American Marketing Association em 2007 e os vários estudos publicados no Journal of Macromarketing (KILBOURNE; CARLSON, 2008; LAYTON, 2009; LEE; CHERRIER; BELK, 2013). No campo particular de marketing turístico e de lugares, essa realidade está evidentemente manifesta em alguns estudos recentes (OVIEDO-GARCIA; CASTELLANOS-VERDUGO; MARTIN-RUIZ, 2008; MAI; RAHTZ; SHULTZ, 2013; JAMAL; CAMARGO, 2013). O entendimento central é de que o funcionamento dos sistemas agregados de marketing precisa gerar valor a todos os agentes envolvidos, distribuindo seus resultados de forma equilibrada e promovendo externalidades positivas nas formas de qualidade de vida e desenvolvimento econômico (FRY; POLONSKY, 2004; LAYTON, 2011; HILL; MARTIN, 2014). 
Com base nesta perspectiva, analisamos o marketing de lugares em uma perspectiva que vai além de envolver os interesses de turistas, exportadores, investidores, indústrias, sedes de corporações e novos residentes, conforme proposto na visão clássica de Kotler, Haider e Rein (1993). Na visão acima apresentada, uma perspectiva de interesse social para marketing turístico e de lugares deve buscar atender também, e primordialmente, aos interesses dos residentes do lugar. A partir do entendimento da função pública do marketing de lugares, fica fácil compreender como os agentes residentes se destacam dentre os públicos interessados do marketing turístico e de lugares que demandam maior atenção e importância.

Entendemos que uma visão de marketing turístico e de lugares que priorize os residentes completa o ciclo do processo operacional desse campo especializado de conhecimento e prática, superando as dificuldades e críticas clássicas do campo de aplicação mais recorrente, que é o marketing turístico. De fato, em termos teóricos, o marketing turístico é questionado por direcionar os benefícios para as pessoas que não são do lugar, em detrimento, eventualmente, daqueles que vivem o dia a dia do lugar (MAI; RAHTZ; SHULTZ, 2013). Com efeito, mesmo se pensarmos no marketing de lugares como uma ação estritamente econômica, podemos claramente perceber como a qualidade de vida dos residentes é um fator que atrai para um lugar investimentos, compradores, turistas, visitantes, novos moradores, entre outros, gerando dessa forma mais valor para o local.

$\mathrm{Na}$ presente pesquisa, perpassaremos pelas diferentes tendências nas pesquisas de marketing turístico e de lugares até chegarmos aos estudos sobre qualidade de vida, apego e satisfação com o lugar de residência. Nosso objetivo central foi desenvolver um melhor entendimento sobre os fatores condicionantes que levam ao sentimento de bem estar dos residentes e as suas devidas implicações para as políticas públicas. Estudos com finalidade semelhantes vêm sendo realizados (HORELLI, 2006; INSCH; FLOREK, 2008; MOSER, 2009; INSCH, 2010; ZENKER, 2012; ZENKER; RÜTTER, 2014), com diversos construtos analisados. Neste estudo, tomamos como recortes os contrutos satisfação e apego ao lugar, além de qualidade de vida percebida.

Além dessa introdução, o trabalho está construído com a exposição, no item 2, da teoria que suporta a associação entre os construtos de base. No item 3, temos a exposição das decisões sobre o método da pesquisa empírica realizada, e no item 4, temos os resultados dessa fase. Por fim, no item 5, temos as considerações finais do estudo, com as conclusões gerais, as limitações da pesquisa e as recomendações de outros estudos. 


\section{Referencial Teórico}

Os estudos acerca do marketing turístico e de lugares estão em amplo desenvolvimento dentro da literatura de marketing. Na orientação de estudos de turismo, normalmente a finalidade é subsidiar governos e agentes do trade turístico a atrair e fidelizar turistas a um determinado destino. Na perspectiva mais ampla de marketing de lugares, Hankinson (2004) indica um desenvolvimento entre diferentes perspectivas acadêmicas. Por exemplo, na literatura de planejamento urbano temos uma visão mais macro sobre o funcionamento social e economicamente eficiente do lugar; neste caso o papel do marketing é o de promover a imagem do lugar de forma a atingir esses objetivos. Nessa linha, o marketing turístico e de lugares refere-se à aplicação do modelo tradicional de administração de marketing, utilizandose das suas ferramentas, conceitos, modelos, técnicas e preceitos, e aplicando-os a um determinado lugar, seja um bairro, uma cidade, uma região, ou até mesmo a um país (cf. HANKISON, 2004a; KOTLER; HAIDER; REIN, 1993).

Convencionalmente, dentro dos estudos de psicologia ambiental, o lugar é conceituado como sendo locações físicas específicas, associadas com significados simbólicos e com emoções. São analisados fatores de congruência entre a identidade dos cidadãos e a noção de lugar, de pertencimento, e como esses fatores influenciam em uma série de comportamentos dos residentes de um lugar (DEVINE-WRIGHT, 2011). Uma série de aspectos da existência humana ocorre em algum tipo de ambiente, e as transações dentro desse ambiente são importantes e tem consequências tanto para as pessoas como para seus mundos naturais ou artificialmente construídos (GIFFORD, 2014).

Nas publicações convencionais dos estudos da área de marketing turístico e de lugares, no entanto, é notável uma tendência à utilização das estratégias do marketing comercial tradicional na promoção de lugares ${ }^{3}$, com o foco na atração dos agentes externos (todos os stakeholders acima mencionados, menos os residentes). Nessas pesquisas, é notável a associação do lugar a um produto comercial, mais especificamente, a uma marca, o que se chama de place branding, com a corrente preocupação na composição da imagem do lugar, o place identity (cf. KOTLER; HAIDER; REIN, 1993; KOTLER; GERTNER; 2002; BRADLEY; HALL; HARRISON, 2002; PAPADOPOULOS, 2004; KAVARATZIS, 2004;

${ }^{3}$ Utilizamos o termo "lugar" para nos referir a cidades, estados, regiões e/ou países. 
HANKINSON, 2004, 2007; HANNA; ROWLEY, 2008; HANSEN, 2010; MAK; 2010; entre outros).

De acordo com Hankinson (2004), este campo especializado de conhecimento e prática envolve a natureza multifacetada dos lugares, com foco em áreas específicas da atividade econômica como turismo, varejo e feiras (WARNABY; BENNISON; DAVIES, 2005; AZIZ; YENG, 2011), atividades culturais (ALVES; CERRO; MARTINS, 2010) e eventos esportivos (JONES, 2005; EDENSON; MILLINGTON, 2008). Hankinson (2004) realça especialmente o conceito de place branding, que consiste em tratar o lugar como uma marca (cf. ZENKER, 2009, 2011), pela avaliação de um lugar da mesma forma que tratamos um produto a partir de uma perspectiva de gestão de marca, criando identidade, diferenciação e, consequentemente, gerenciando seu valor e conhecimento.

Além dessas abordagens, a literatura mais atual na área de marketing turístico e de lugares tem dado enfoque em um grupo de interesse específico, que são os residentes. Por exemplo, Rogerson (1999) discutiu a qualidade de vida do residente em conjunto com a competitividade de cidades; Moranta e Urrútia (2005) buscaram compreender o apego das pessoas com os lugares a partir de uma perspectiva de apropriação do espaço; Raymond, Brown e Weber (2010) e Rollero e Picolli (2010) também analisam os fatores de apego do residente ao lugar; Insch e Florek (2008), Insch (2010), e Zenker, Petersen e Aholt (2012) enfocaram fatores associados à satisfação dos residentes de um lugar; e Gilboa e Herstein (2012) buscam relacionar status do lugar e 'lealdade' ao lugar com o bem estar dos residentes.

Nesta pesquisa tomamos por desafio analisar conjuntamente alguns dessses temas. Escolhemos avaliar a qualidade de vida percebida, o apego e a satisfação com o lugar. Nos itens seguintes exibimos maiores detalhes sobre cada um desses construtos.

\subsection{Qualidade de vida dos residentes}

Neste artigo, tomamos por referência que o sistema de marketing turístico e de lugares deve ter um foco especial nos residentes, e deve ser realçada a preocupação, além da meta de promoção do desenvolvimento econômico e social, com a promoção da qualidade de vida e com o bem-estar dos residentes. Essa perspectiva está pautada numa crescente orientação de marketing que propõe o sistema de marketing como gerador de qualidade de vida das pessoas (cf. LEE; SIRGY, 2004; LAYTON, 2007, 2009). 
A qualidade de vida pode ser definida em termos de quão satisfatoriamente as necessidades humanas estão sendo atendidas, ou qual o grau em que os indivíduos ou grupos avaliam a satisfação em diferentes domínios de suas vidas. Segundo Moser (2009), o bem-estar dos indivíduos é expresso não apenas a partir de sua satisfação com relações interpessoais, vida em família, emprego, carreira, saúde e finanças, mas também em termos das relações com os diferentes aspectos do ambiente físico o qual faz parte. Para Horelli (2006), o ambiente em que as pessoas vivem é um determinante contextual tão importante, que sempre deveria estar incluso nos estudos sobre qualidade de vida e bem-estar.

De acordo com Diener et al. (1985), o bem-estar subjetivo é composto por três componentes: afeto positivo, afeto negativo e satisfação com a vida. Os dois primeiros componentes se referem a aspectos afetivos e emocionais do construto, enquanto o último se refere a aspectos de julgamento cognitivo. Apesar da importância dos aspectos afetivos, o que tem sido mais recorrentemente tomado como objeto de interesse em pesquisas empíricas é a satisfação com a vida. Aqui seguimos esta tendência, tomando a satisfação com a vida como 'proxy' da qualidade de vida percebida dos residentes.

Ainda sobre o estudo de Diener et al. (1985), os autores propuseram uma escala para medição da satisfação com a vida, a SWLS - Satisfaction with Life Scale (Escala de satisfação com a vida). Uma extensão dessa escala, com uma adaptação para domínios específicos da vida, foi proposta por Alfonso et al. (1996), que adicionaram, além da dimensão de satisfação com a vida em geral, a satisfação com a vida social, com a vida sexual, com o self, com a aparência física, com a família, com a instituição de ensino, com o trabalho e com o relacionamento.

Neste estudo analisamos este construto como consequência da safisfação com o lugar e do apego do residente ao lugar. Este último está melhor exposto a seguir.

\subsection{Apego ao lugar}

Conforme sinalização da literatura, além dos fatores de qualidade de vida, o nível de apego que a pessoa desenvolve com um lugar é determiante para o desejo dessa pessoa de querer viver no lugar e sua percepção de bem-estar. Ou seja, a maneira como as pessoas percebem e vivenciam seu ambiente pode ser um fator central de explicação de sua qualidade de vida percebida como residentes (Rollero; Piccoli, 2010).

De acordo com Moser (2009), o apego ao lugar é um vínculo positivo que as pessoas 
desenvolvem ao longo do tempo com o ambiente social e físico em que convivem. Esse apego perpassa os aspectos cognitivos, motivacionais e comportamentais do indivíduo. De maneira consonante, Rollero e Piccoli (2010) afirmam que o apego ao lugar engloba diferentes aspectos do vínculo pessoa-lugar e envolve as relações entre afetos e emoções, conhecimento e credos, e comportamentos e ações em relação a um lugar.

Em relação à literatura de marketing de destinos turísticos ou de lazer, por exemplo, encontramos uma linha de estudos que entende o apego ao lugar como um conceito útil para compreender os aspectos do lazer e do comportamento turístico de um indivíduo (ALEXANDRIS; MELIGDIS, 2006). Gross e Brown (2006) chegam a afirmar que uma comparação do nível de apego ao lugar entre diferentes regiões turísticas auxilia no entendimento das características que ajudam a delinear as interpretações dos turistas em relação ao lugar, e esse conhecimento possui implicações para os gestores de marketing dos destinos para os quais é crucial saber distinguir as características que são substituíveis daquelas que são percebidas como exclusivas de um determinado lugar.

No contexto de marketing de cidades, percebemos uma maior tendência de estudos preocupados com a competitividade, como é o caso do place branding. Nesses estudos, quando se fala em residentes, o foco é sobre como atrair e manter os novos, e uma das estratégias utilizadas é fomentar o apego ao lugar. O trabalho de Gilboa e Herstein (2012), por exemplo, utiliza a perspectiva de analisar o lugar como uma marca, sinalizando semelhanças nas definições entre apego ao lugar e apego à marca (brand attachment; os autores utilizam o termo de lealdade ao lugar, a partir do conceito de lealdade à marca).

Em relação às dimensões que compõem do apego ao lugar, Raymond, Brown e Weber (2010) identificaram na literatura especializada três contextos de análise sobre apego ao lugar: o contexto pessoal (identidade com o lugar, dependência com o lugar e raízes com o lugar), o comunitário (apego à vizinhança, pertencimento e familiaridade) e o do meio natural (conexão e afinidade com a natureza, e identidade com o ambiente).

As dimensões de identidade e dependência com o lugar foram escolhidas para efeitos dessa pesquisa pois fazem parte do contexto pessoal do apego ao lugar, que é o foco do presente estudo. De acordo com os autores, a identidade com o lugar corresponde às dimensões do self em relação ao lugar que define quem somos; já a dependência do lugar é o grau em que o 
ambiente físico provê condições para manter uma determinada forma de viver naquele lugar.

Diante desses recortes temáticos, percebemos que há, na literatura específica de marketing turístico e de lugares, uma lacuna em relação à utilização do conceito de apego ao lugar voltado especificamente para o residente, de forma a produzir conhecimento sobre os aspectos que levam a esse apego e a determinados comportamentos do residente em relação ao lugar. Para entender melhor a formação do apego, as evidências da literatura são de que o construto tem associação com a satisfação com o lugar, tópico detalhado a seguir.

\subsection{Satisfação com o lugar}

Sabemos que, em marketing, a satisfação com um produto ou serviço está diretamente atrelada à comparação entre o que os clientes esperam receber e o que efetivamente recebem, ou seja, é a comparação entre o desempenho percebido de um produto e as expectativas do cliente. Além disso, o nível de satisfação dos clientes deve ser medido com regularidade, já que a forma mais eficaz de reter os clientes é através da geração de sua satisfação (Kotler; Keller, 2006).

Concernente aos estudos da área de satisfação com o lugar, a busca está em analisar fatores indicadores dessa satisfação. De acordo com Kotler, Haider e Rein (1993), por exemplo, os critérios que são considerados como geradores de satisfação em um lugar são: o custo de vida, emprego, nível de criminalidade, a oferta de estrutura para saúde e de agentes de saúde, transporte, educação, artes, lazer e clima. De forma mais resumida, Rainisto (2003) afirma que a atratividade de um lugar é oriunda da abertura de novas indústrias, muitas oportunidades de trabalho e nível de qualidade de vida.

Ademais, conforme Insch (2010), há uma lacuna na literatura da área em termos de determinar o grau de importância ou de satisfação que os residentes atribuem a diversos aspectos do lugar onde vivem. A autora afirmou que pouco se sabe sobre o que determina a satisfação com o lugar de residência. Além dos fatores de predição, temos ainda desafios em termos de proposições de medidas adequadas e de realização de estudos empíricos sobre o assunto (realçamos que esforços para proposição de métricas de satisfação com o lugar têm sido feitos; Zenker, Peterson e Aholt (2012), por exemplo, validaram uma escala específica para medir a satisfação do residente com a cidade).

No item seguinte delimitamos as relações e o modelo estrutural de relacionamento entre os construtos acima expostos. 


\subsection{Hipóteses da pesquisa}

Conforme observamos na literatura especializada, podemos notar que a satisfação com o lugar afeta positivamente o grau de apego do residente ao lugar em que vive (Insch; Florek, 2008; Walker; Ryan, 2008; Zenker; Petersen; Aholt, 2012). Vimos ainda que o apego ao lugar é oriundo ainda de vínculos que as pessoas criam experiências agradáveis que as pessoas vivenciam naqueles lugares. Tomando o dimensionamento do apego de Raymond, Brown e Weber (2010), enunciamos as duas hipóteses a seguir:

H1 - Altos níveis de satisfação com o lugar influenciam positivamente altos níveis de apego (identidade) com o lugar;

H2 - Altos níveis de satisfação com o lugar influenciam positivamente altos níveis de apego (dependência) com o lugar;

Adicionalmente, e considerando estudos como o de Moser (2009) e o de Rollero e Piccoli (2010), pudemos observar que a qualidade de vida percebida pelos residentes de um lugar é influenciada pelo grau de apego que o indivíduo tem com o lugar em que vive, além do nível de sua satisfação com o lugar. Assim, podemos lançar as seguintes hipóteses:

H3 - Altos níveis de satisfação com o lugar influenciam positivamente altos níveis de qualidade de vida percebida;

H4 - Altos níveis de apego (identidade) ao lugar influenciam positivamente altos níveis de qualidade de vida percebida;

H5 - Altos níveis de apego (dependência) ao lugar influenciam positivamente altos níveis de qualidade de vida percebida.

Diante do exposto, temos um modelo associando os construtos, em que o apego ao lugar se posiciona como fator intermediário entre satisfação como lugar e qualidade de vida percebida pelos residentes. Uma visualização do modelo estrutural está indicada na Figura 1. 


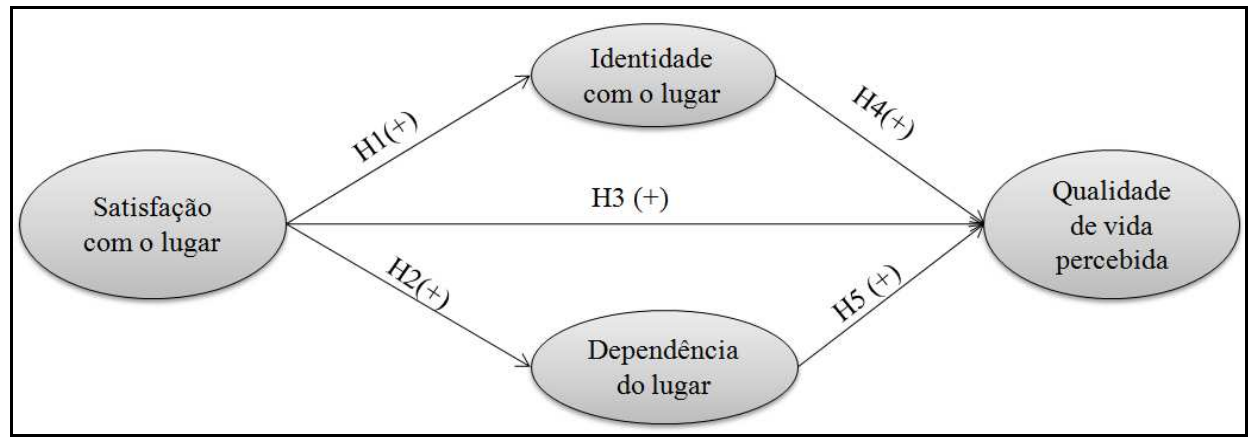

Figura 1 - Modelo da Pesquisa

Fonte: Elaboração própria

Nesta pesquisa tomamos o desafio de testar empiricamente esse modelo, a partir de um estudo de campo na modalidade de survey. Os detalhes metodológicos estão indicados no item 3, e os resultados estão no item 4.

\section{Método}

Neste item apresentamos as decisões metodológicas, com informações sobre as decisões de mensuração, o desenho do trabalho de campo e a análise de dados. Concernente às escalas de mensuração dos construtos, para os contrutos de qualidade de vida percebida (com 5 itens oriundos da escala SWLS - Satisfactionwith Life Scale, proposta por Diener et al. (1985)) e apego ao lugar (com parte da escala proposta por Raymond, Brown e Weber (2010)) foram utilizadas escalas já existentes na literatura. Já para o construto de satisfação com o lugar, optamos pelo desenvolvimento completo de uma nova escala. Foram usados indicadores na forma de afirmações, para aferição em escalas do tipo Likert com 10 pontos (de 1 a 10). Os itens de cada construto estão no anexo deste artigo.

Como nossa intenção não era de fazer generalizações acerca das percepções dos residentes em relação ao lugar que habitam, mas sim testar as relações entre os construtos, utilizamos uma amostra de 415 respondentes, oriundos de diferentes cidades do estado da Paraíba: 139 de João Pessoa; 114 de Campina Grande; 53 de Guarabira; e 109 de outras cidades circunvizinhas a essas três.

Em termos de situação laboral dos respondentes, verificamos que 55,4\% não estavam trabalhando e que 44,6\% exerciam alguma atividade profissional (seja em meio turno ou o dia inteiro). A maioria dos respondentes se autodeclarou jovem, com 44,6\% com idade até 20 anos de idade e $33,7 \%$ com idade entre 21 e 30 anos. Encontramos uma situação equilibrada 
entre os gêneros, sendo $46,5 \%$ do sexo masculino e 53,5 do sexo feminino. A renda familiar dos respondentes se concentrou em 55,2\% em até $\mathrm{R} \$ 2.000,00$ mensais, e 26,5\% indicaram renda familiar entre $\mathrm{R} \$ 2.000,00$ e $\mathrm{R} \$ 4.000,00$ mensais. Referente ao grau de escolaridade dos residentes, obtivemos resultados equilibrados entre ensino médio (41\%) e ensino superior (46,6\%). Além disso, 53\% dos respondentes afirmaram que já moraram em outra cidade contra $47 \%$ que afirmaram nunca haver morado em outra cidade além da que residem atualmente. Por fim, observamos uma média de 18,64 anos de tempo de moradia na cidade em que o respondente morava atualmente, o que denota um bom tempo de experiência com a cidade de residência com uma boa base para emitir opiniões.

$\mathrm{Na}$ análise dos dados, foram utilizadas inicialmente técnicas descritivas, com operacionalização pelo pacote SPSS, para analisar os dados demográficos da amostra e para a análise dos construtos, observando-se nestas últimas os resultados das médias, medianas, desvios padrão, assimetria e curtose de cada um dos itens de mensuração. Na sequência, um conjunto de técnicas convencionais do processo de construção de escalas foi adotado (análise de correlação, análise fatorial exploratória e análise de confiabilidade). Para teste das hipóteses, utilizamos modelagem de equações estruturais, que operacionalizamos através do software WarpPLS, que é o software mais adequado e utilizado para o tipo de modelo proposto nesta pesquisa. Para o construto de satisfação geral, procedemos ainda a análise fatorial confirmatória, utilizando o software estatístico AMOS. Os detalhamentos mais relevantes relativos a essas técnicas, considerando esta pesquisa, estao expostos ao longo da exposição dos resultados no próximo item. Todos os procedimentos foram realizados com base na literatura especializada da área (COSTA, 2011; HAIR et al. 2005; LATTIN; CARROL; GREEN, 2011).

\section{Resultados}

Neste item apresentamos os resultados do trabalho empírico, com uma exposição inicial dos resultados da mensuração dos construtos, seguida pelo teste das hipóteses. Ao final temos a discussão dos resultados.

\subsection{Análise psicométrica das escalas}

Relativo ao construto qualidade de vida percebida, observamos que, para os cinco itens utilizados (vide apêndice), emergiu um único fator, com explicação de 58,6\% da variância 
total (requerido no mínimo 50\%) e com escores fatoriais todos acima de 0,7 (o requerido é de no mínimo 0,4). Esse resultado sinalizou a adequação fatorial das variáveis na mensuração do construto latente. Em complentento, na análise de confiabilidade obtivemos um coeficiente alpha de Cronbach de 0,816, com uma sinalização de consistência interna (era requerido ao menos 0,60 ). Verificamos também que qualquer variável excluída só diminuiria o valor do alpha. Isto viabilizou a agregação dos itens pela média dos escores por respondentes e a posterior extração das medidas descritivas.

Conforme mostra a Tabela 1, neste construto a média dos respondentes foi de 6,21, com mediana de 6,40, ou seja, tivemos medidas de posição central de nível moderado. O desvio padrão foi de 1,92, com a sinalização de dispersão baixa.

Tabela 1 - Medidas Agregadas por Construto

\begin{tabular}{l|c|c|c}
\hline \multicolumn{1}{c|}{ Construtos } & Média & Mediana & Desvio \\
\hline Qualidade de vida percebida & 6,21 & 6,40 & 1,92 \\
Apego (identidade) & 6,69 & 7,00 & 2,56 \\
Apego (dependência) & 5,53 & 5,60 & 2,53 \\
Satisfação geral com a cidade & 5,71 & 5,75 & 2,24 \\
Satisfação com fatores específicos & 5,05 & 5,02 & 1,84 \\
\hline Fonte: Dados da pesquisa (2013)
\end{tabular}

Com relação à dimensão de identidade do construto apego, mensurado com 7 itens, na avaliação da extração fatorial verificamos que apenas um fator teve autovalor acima de 1, correspondendo a 67,03\% da variância total. Em relação aos escores fatoriais, todos ficaram acima de 0,7, com exceção da variável "A cidade onde habito significa muito para mim" que obteve escore de 0,561 . O valor do coeficiente alpha de Cronbach foi de 0,871 , e a exclusão da variável acima relatada aumentaria o valor para 0,931 . Pelo conteúdo do item, e considerando a adequação psicométricas nas demais medidas, decidimos manter este item na escala.

Considerando novamente a Tabela 1, analisando as medidas descritivas dos dados da dimensão identidade do construto apego percebemos, em geral, uma média moderada $(6,69)$ e uma mediana elevada $(7,00)$, assim, os valores de média se mantiveram dentro de níveis moderados a elevados. Em termos de desvio padrão, no geral obtivemos um nível de dispersão moderado.

Já com relação à dimensão dependência do cosntruto apego, que foi mensurada por meio de 5 itens, na extração fatorial apenas um fator apresentou autovalor maior do que 1, explicando $72,44 \%$ da variância total. Adicionalmente, todos os itens obtiveram cargas fatoriais de 0,8 . O 
valor do alpha de Cronbach foi 0,905 o que denota um nível alto de consistência interna (a retirada de qualquer item só diminuiria o alpha de Cronbach). Pelo exposto, temos boa consistência psicométrica também na medição dessa dimensão. Conforme mostra a Tabela 1 , os valores de média e mediana em geral moderados (5,53 e 5,60, respectivamente). Em relação ao desvio padrão, percebemos uma dispersão geral em nível moderado.

Por fim, no construto satisfação geral com a cidade procedemos à criação de uma nova métrica. Selecionamos na literatura uma série de 9 itens, e após uma série de depurações e procedimentos de validação, conforme recomendações de Costa (2011), dois itens foram excluídos, restando, 7 outros que foram incluídos no questionário.

Tendo em vista que estamos trabalhando com uma escala que ainda não existia (diferente das demais acima apresentadas), nesses conjuntos de itens foi itens realizamos uma análise fatorial confirmatória, por meio do software AMOS. Este procedimento permite analisar, além das medidas convencionais (variância extraída e escores fatoriais), uma série de outras medidas de ajustamento. Foram procedidas diversas iterações, na busca de encontrar resultados estatísticos que compatibilizassem, ao final, o conteúdo de cada item. Após as iterações, o fator ficou bem ajustado com 4 variáveis, com as três outras variáveis sendo excluídas da análise subsequente.

Tabela 2 - Análise Fatorial Confirmatória da Satisfação Geral com a Cidade

\begin{tabular}{|c|c|c|c|}
\hline \multicolumn{2}{|c|}{ Variáveis } & Escores & Valores $\mathrm{t}(\mathrm{CR})^{*}$ \\
\hline \multicolumn{4}{|c|}{ PAINEL 1 - ITENS E ESCORES FATORIAIS } \\
\hline \multicolumn{2}{|c|}{ O que tem na cidade onde resido é exatamente o que preciso } & 0,778 & 17,407 \\
\hline \multicolumn{2}{|c|}{ Eu estou satisfeito com o que tenho a disposição na cidade onde moro } & 0,880 & 20,187 \\
\hline \multicolumn{2}{|c|}{ Minha experiência com que tenho na cidade onde resido é satisfatória } & 0,816 & 18,510 \\
\hline \multicolumn{2}{|c|}{ Eu acredito que a cidade onde vivo me fornece bons serviços } & 0,815 & - \\
\hline \multicolumn{4}{|c|}{ PAINEL 2 - MEDIDAS DE AJUSTAMENTO } \\
\hline Medida de ajustamento & Observado & \multicolumn{2}{|c|}{ Requisito de adequação } \\
\hline Qui-quadrado $\left(x^{2}\right)$ & 6,972 & \multicolumn{2}{|c|}{$=0$} \\
\hline Graus de liberdade $(\mathrm{gl})$ & 2 & \multicolumn{2}{|r|}{-} \\
\hline Razão $y^{2} / g l$ & 3,486 & \multicolumn{2}{|r|}{$<5,000$} \\
\hline p-valor & 0,031 & \multicolumn{2}{|r|}{$>0,050$} \\
\hline GFI & 0,991 & \multicolumn{2}{|r|}{$>0.900$} \\
\hline CFI & 0,995 & \multicolumn{2}{|r|}{$>0.900$} \\
\hline RMSEA & 0,077 & \multicolumn{2}{|r|}{$<0,080$} \\
\hline
\end{tabular}

* Todos os valores significativos a $\mathrm{p}<0,001$

Fonte: Dados da pesquisa (2013)

Os resultados, que estão expostos na Tabela 2, mostram uma adequação muito boa dos escores (todos acima de 0,77, e estatisticamente não nulos), e as medidas de ajustamento estão 
todas dentro dos limites sugeridos na literatura de mensuração (COSTA, 2011). O alpha de Cronbach final foi de 0,893 , o que indica elevada consistência interna no conjunto de itens. A partir da análise das medidas descritivas, mostradas na Tabela 1, podemos observar que em geral os valores de média $(5,71)$ e mediana $(5,75)$ em níveis moderados, em termos de nível de dispersão, no geral encontramos um desvio padrão em nível moderado em 2,24.

\subsection{Teste do modelo}

Para o procedimento de teste do modelo para análise de cada hipótese foi utilizado o software WarpPLS. Esse software é utilizado para modelagem de equações estruturais (SEM), com facilidade de uso por possuir um guia de interface passo-a-passo do usuário, o dispositivo identifica relações não lineares e as estimativas dos coeficientes, além de modelar as relações lineares, utilizando um algoritmo de regressão padrão PLS.

$\mathrm{Na}$ análise, observamos os valores extraídos dos parâmetros de influência estimados, e do pvalor para realizar a avaliação das relações propostas no modelo teórico. Como forma de aprofundar as análises, e analisar a potencial existência de variações associadas às cidades, a extração destas medidas foi feita com as medidas globais e por cidade (Tabela 3).

Tabela 3 - Teste das Hipóteses Geral e por Cidade

\begin{tabular}{l|c|c|c|c|c}
\hline \multirow{2}{*}{ Hip } & \multirow{2}{*}{ Descrição } & \multicolumn{3}{|c}{ Parâmetros estimados (p-valor)* } \\
\cline { 3 - 6 } & & GERAL & JP & CG & OUT \\
\hline H1 & Satisfação lugar $\rightarrow$ apego (identidade) & $0,784(0,000)$ & $0,766(0,000)$ & $0,811(0,000)$ & $0,789(0,000)$ \\
H2 & Satisfação lugar $\rightarrow$ apego (dependência) & $0,829(0,000)$ & $0,778(0,000)$ & $0,814(0,000)$ & $0,845(0,000)$ \\
H3 & Satisfação lugar $\rightarrow$ qualidade de vida & $0,511(0,000)$ & $0,461(0,000)$ & $0,702(0,000)$ & $0,528(0,000)$ \\
H4 & Apego (identidade) $\rightarrow$ qualidade de vida & $0,041(0,217)$ & $-0,005(0,489)$ & $0,152(0,143)$ & $0,098(0,185)$ \\
H5 & Apego (depend.) $\rightarrow$ qualidade de vida & $0,210(0,002)$ & $0,268(0,008)$ & $0,238(0,063)$ & $0,121(0,149)$ \\
\hline *Valores com (0,000) indicam p-valor menor que 0,001 & \\
Fonte: Dados da pesquisa (2013)
\end{tabular}

De maneira mais destacada, tivemos as hipóteses $\mathrm{H} 1, \mathrm{H} 2$ e $\mathrm{H} 3$ confirmadas em todas as extrações realizadas. Também percebemos a rejeição da hipótese H4 tanto na amostra global como por cidade (seu p-valor foi maior que 0,05 e o parâmetro estimado resultou em um valor muito pequeno), o que nos sugeriria que a dimensão identidade do apego não teria associação de predição com o nível de qualidade de vida percebida. Adicionalmente, podemos perceber que a hipótese H5 não foi totalmente aceita quando operacionalizamos os testes em diferentes cidades. Tais resultados, obviamente, não eram esperados, já que identificamos na literatura estudos que colocam o apego como uma condição prévia para a percepção de qualidade de vida dos residentes. 
Esses resultados nos levaram a uma nova análise de conteúdo dos itens que compõem as duas dimensões do apego (identidade e dependência). Assim, na escala de dependência, observamos uma forte correspondência de conteúdo com o construto satisfação com o lugar, já que possui elementos de avaliação do lugar, conforme evidenciado nas variáveis 'Eu tenho mais satisfação em morar na cidade onde moro do que teria em qualquer outro lugar'; 'Nenhum lugar se compara à cidade onde habito'; ou 'A cidade onde habito é o melhor lugar para fazer o que gosto'. Em termos de correlação, nas medidas gerais, os construtos apego (dependência) e satisfação geral com o lugar obtiveram um alto grau de correlação $(0,825)$, o que corrobora com a análise de conteúdo.

Essa reflexão nos levou a adotar a modelagem de equações estruturais pela estratégia de 'desenvolvimento de modelos' proposta por Hair et al. (2005), que prevê a necessidade de se buscar mudanças possíveis no modelo como forma de melhoria do resultado, mesmo quando o modelo de hipóteses já tiver sido definido. Trata-se, segundo esses mesmos autores, da reespecificação de um modelo na qual se buscam promover melhorias no ajuste do modelo ou de correspondências com a literatura estudada.

Assim, decidimos com base nessa estratégia indicada por Hair et al. (2005), realizar o incremento das análises entre os construtos, através da retiradada dimensão apego-dependência do modelo, para assim realizar novos testes no sentido de verificar a adequação dessa nova configuração do modelo. Na Tabela 4 apresentamos os resultados obtidos dessa nova modelagem.

Tabela 4 - Testes das Hipóteses do Novo Modelo

\begin{tabular}{|c|c|c|c|c|c|}
\hline \multirow{2}{*}{ Hip. } & \multirow{2}{*}{ Descrição } & \multicolumn{4}{|c|}{ Beta (p-valor)* } \\
\hline & & GERAL & $\mathbf{J P}$ & CG & OUT \\
\hline H1 & Satisfação lugar $\rightarrow$ apego (identidade) & $0,784(0,000)$ & $0,766(0,000)$ & $0,811(0,000)$ & $0,789(0,000)$ \\
\hline H3 & Satisfação lugar $\rightarrow$ qualidade de vida & $0,697(0,000)$ & $0,567(0,000)$ & $0,820(0,000)$ & $0,586(0,000)$ \\
\hline $\mathrm{H} 4$ & Apego (identidade) $\rightarrow$ qualidade de vida & $0,141(0,002)$ & $0,141(0,099)$ & $0,060(0,280)$ & $0,155(0,038)$ \\
\hline
\end{tabular}

Conforme podemos observar, a retirada da dimensão dependência do apego resultou na melhoria da aceitação da hipótese $\mathrm{H} 4$, que antes estava sendo totalmente refutada, tanto nas medidas gerais como por cidade. Com a nova modelagem, a hipótese passou a ser aceita nas medidas gerais, e somente refutada na cidade de Campina Grande. Isto nos mostra evidências de que a primeira modelagem teve, possivelmente, um vício em relação ao conteúdo dos itens de dependência do construto apego. 
Com esses resultados, pudemos confirmar um modelo final de relações entre os construtos 'satisfação geral com o lugar', 'apego com o lugar (identidade)', e 'qualidade de vida percebida' (Figura 2), com as seguintes relações confirmadas:

- Altos níveis de satisfação com o lugar influenciam positivamente altos níveis de apego ao lugar;

- Altos níveis de satisfação com o lugar influenciam positivamente altos níveis de qualidade de vida percebida;

- Altos níveis de apego ao lugar influenciam positivamente altos níveis de qualidade de vida percebida.

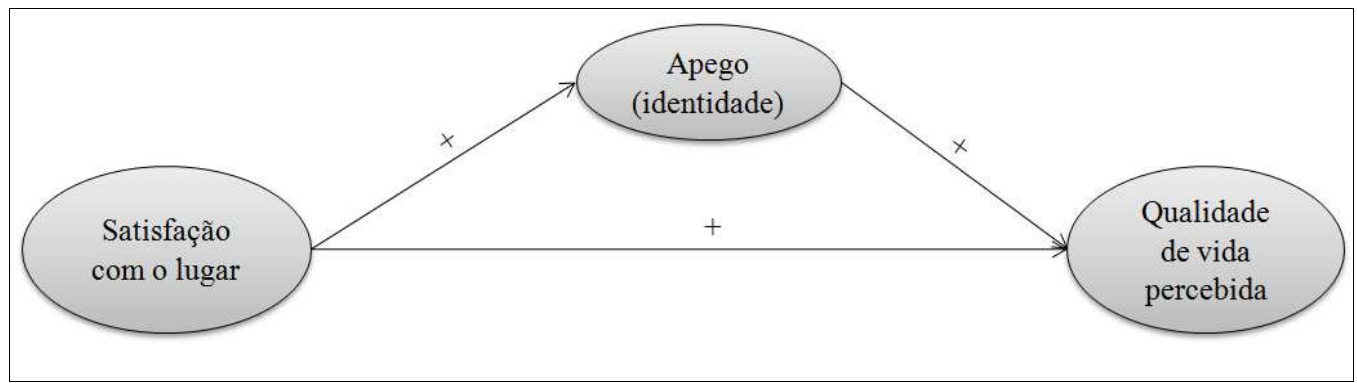

Figura 2 - Novo Modelo

Fonte: Elaboração própria

\subsection{Discussão das hipóteses}

A partir da revisão teórica desenvolvida nessa pesquisa, era esperado que, na medida em que o residente de um lugar tivesse um maior grau de satisfação com aquele lugar, maior seria seu nível de apego àquele lugar (cf. INSCH; FLOREK, 2008; WALKER; RYAN, 2008; ZENKER; PETERSEN; AHOLT, 2012). Em conformidade com esses estudos prévios, os dados do trabalho de campo confirmaram esta suposição na hipótese $\mathrm{H} 1$, de que o nível de satisfação com o lugar influência positivamente o nível de identidade com o lugar, tanto no modelo original como no novo modelo.

O mesmo ocorreu com a expectativa de que quanto mais o residente tem satisfação com o lugar maior seu grau de dependência, conforme hipótese H2, que ficou apenas no modelo original. Isto sinaliza a necessidade dos gestores de lugares buscarem formas consistentes de aumentar o grau de satisfação dos residentes com o lugar e assim conquistar maiores níveis de apego ao lugar. 
A busca, por parte dos gestores do lugar, de um aumento do nível de apego ao lugar dos residentes encontra justificativa no argumento de Morranta e Urrútia (2005) de que pessoas que possuem fortes vínculos com o lugar em que residem podem ter comportamentos ecologicamente responsáveis e uma maior participação no lugar em que vivem, ou seja, as pessoas possuirão um maior comprometimento com o lugar. Em uma perspectiva convergente, Zenker, Petersen e Aholt (2012), argumentam que esse comprometimento pode ser um indicador de um comportamento ativo de cidadania, já que mede o nível em que as pessoas se sentem responsáveis pelo lugar. Em suma, maior apego é algo bastante positivo para os lugares e o apego é algo que precisa ser incentivado.

A satisfação com o lugar também demonstrou ter uma relação direta (sem a intermediação do apego) e positiva na percepção de qualidade de vida pelos residentes de acordo com o trabalho empírico da pesquisa, conforme estava previsto na hipótese H3. Esta hipótese foi confirmada tanto no modelo original como no novo modelo, reafirmando-se a expectativa de associação já prevista na literatura especializada (cf. INSCH; FLOREK, 2008; MOSER, 2009; ROLLERO; PICCOLI, 2010). Percebe-se assim a importância de conhecer bem e investir em fatores que levam à satisfação com o lugar já que isso promoverá uma maior percepção de qualidade de vida pelos moradores.

Sendo a promoção da qualidade de vida e do bem-estar dos residentes uma das principais saídas do sistema de trocas do marketing de lugares orientado para os residentes (conforme nossa proposição na Figura 4), é evidente a necessidade de fomentar ações que promovam essa percepção de qualidade de vida. $\mathrm{Na}$ análise da influência do apego ao lugar na qualidade de vida percebida, pôde-se constatar que, no modelo original, em termos de medidas gerais, a hipótese $\mathrm{H} 4$ foi refutada enquanto a $\mathrm{H} 5$ foi aceita (foram exatamente esses resultados que nos levaram a re-especificação do modelo, considerando apenas a dimensão identidade como formadora do construto apego).

Assim, no novo modelo, obtivemos a confirmação da influência positiva do apego ao lugar na qualidade de vida percebida, em conformidade com estudos já consolidados na área (cf. MOSER, 2009; ROLLERO; PICCOLI, 2010). Esse resultado reafirma a força que o apego ao lugar tem como gerador da percepção de qualidade de vida pelos residentes de um lugar.

Vale ressaltar, no entanto, o resultado observado do teste dessa hipótese H4, no novo modelo, 
para a cidade de Campina Grande, onde a hipótese foi refutada. É um resultado inesperado, visto que a média do construto apego (identidade) em Campina Grande foi a mais alta $(7,33)$ na comparação com as médias das demais cidades, assim como aconteceu com o construto qualidade de vida percebida $(6,80)$. Isso nos traz indicações de que a qualidade de vida percebida pelos residentes dessa cidade pode não ser oriunda do grau de apego à cidade, o que denota a necessidade de estudos qualitativos mais aprofundados para investigar as particularidades dessas relações na cidade de Campina Grande.

\section{Considerações finais}

Este estudo se configurou a partir de uma lógica de marketing turístico e de lugares voltada, principalmente, para o atendimento do interesse do residente, na promoção da sua qualidade de vida. A premissa foi de que o marketing turístico e de lugares deve estar pautado numa perspectiva do 'marketing voltado para o interesse público', no qual o agente residente se torna o principal público interessado e demandante de maior foco e atenção na ação de marketing.

Utilizando uma amostra de residentes em diferentes cidades, foi possível compreender como as relações entre satisfação ao lugar, apego ao lugar e qualidade de vida se dão, com os resultados demonstrando que a satisfação com o lugar tem uma forte influência positiva tanto no nível de apego ao lugar, como no grau de percepção de qualidade de vida pelos residentes. Também pudemos perceber que o nível de apego do residente ao lugar tem impacto positivo nessa percepção de qualidade de vida das pessoas que habitam em um determinado lugar.

Os resultados desta pesquisa possuem direta implicação prática na atuação dos gestores de lugares, no sentido de possibilitar-lhes o entendimento de fatores que levam a percepção de qualidade de vida por parte dos residentes dos lugares que gerenciam. Um lugar cujos residentes têm uma boa qualidade de vida se torna um lugar atrativo investimentos, novas empresas, novos residentes, visitantes etc., fomentando o desenvolvimento econômico do lugar.

Em termos acadêmicos, essa pesquisa pôde contribuir para a identificação e promoção de uma área complementar de estudos em marketing turístico e de lugares, além das identificadas por Hankinson (2004). Em nosso entendimento, avançamos na literatura da área ao testarmos um conjunto de relações simultaneamente, a partir da modelagem de equações estruturais, já que o que encontramos na literatura foram relações em separado com a satisfação com o lugar 
sendo um antecedente do apego ao lugar.

Embora tenhamos alcançado satisfatoriamente os objetivos traçados, ficaram no estudo algumas limitações. Assim, uma primeira limitação refere-se ao escopo do modelo da pesquisa, que se resumiu a estudar as relações entre satisfação com o lugar, apego ao lugar e qualidade de vida percebida, o que restringiu o entendimento de outros possíveis construtos e suas inter-relações. Recomendamos, portanto, que outros estudos analisem outros construtos além desses aqui avaliados.

Outro ponto de fragilidade foi a amostra obtida, que, apesar de ter tornado o estudo consistente e estar consonante com pesquisas na área, consideramos que a construção amostral foi limitada. Assim, se faz importante que os próximos estudos utilizem amostras maiores e em mais cidades. Ademais, estudos qualitativos serão necessários para o aprofundamento das análises das relações entre os construtos, além de propiciar a identificação das especificidades de diferentes lugares que o tipo de método desse estudo não logrou alcançar.

\section{Referências}

ALEXANDRIS, K.; KOUTHOURIS, C.; MELIGDIS, A. Increasing customers' loyalty in a skiing resort: The contribution of place attachment and service quality. International Journal of Contemporary Hospitality Management, v. 18, n. 5, p. 414-425, 2006.

ALFONSO, V. C.; ALLISON, D. B.; RADER, D. E.; GORMAN, B. S. The extended satisfaction with life scale: development and psychometric properties. Social Indicators, v. 38, n. 3, p. 275 - 301, 1996.

ALVES, H. M. B.; CERRO, A. M. C.; MARTINS, A. V. F. Impacts of small tourism events on rural places. Journal of Place Management and Development, v. 3, n. 1, p. 22 - 37, 2010.

AZIZ, K. B. A.; YENG, L. W. Exploring the potential of a night market as a tourist attraction. International Journal of Business and Social Science, v. 2, n. 22, 2011.

BRADLEY, A.; HALL, T.; HARRISON, M. Selling cities - promoting new images for meetings tourism. Cities, v. 19, n. 1, p. 61 - 70, 2002.

BURGUETE, J. L. V. Pasado, presente y futuro de las dimensiones pública y social en el desarrollo conceptual del marketing. Revista Internacional de Marketing Público y no lucrativo, v. 1, n.1, p. 9-34, 2004.

COSTA. F. J. Marketing e sociedade: uma visão disciplinar. Mimeografado, 2009.

COSTA, F. J. Mensuração e desenvolvimento de escalas: aplicações em Administração. Rio de Janeiro, 2011.

DEVINE-WRIGHT, Patrick. Developing understandings of place attachment and identity: Critical reflections on Environmental Psychology and Human Geography perspectives. 2011. 
DIENER, E.; EMMONS, R. A.; LARSEN, R. J.; GRIFFIN, S. The satisfaction with life scale. Journal of Personality Assessment, v. 49, n. 1, 1985.

EDENSON, T.; MILLINGTON, S. 'This is Our City': branding football and local embeddedness. Global Networks, v. 8, n. 2, p. 172 - 193, 2008.

FRY, M.-L.; POLONSKY, M. J. Examining the unintended consequences of marketing. Journal of Business Research, v, 57, p. 1303-1306, 2004.

GIFFORD, Robert. Environmental psychology matters. Psychology, v. 65, n. 1, p. 541, 2014.

GILBOA, S.; HERSTEIN, R. Place status, place loyalty and well being: an exploratory investigation of Israeli residents. Journal of Place Management and Development, v. 5, n. 2, p. 141 - 157, 2012.

GROSS, M. J.; BROWN, G. Tourism experiences in a lifestyle destination setting: The roles of involvement and place attachment. Journal of Business Research, v. 59, n. 6, p. 696-700, 2006.

HAIR Jr.; ANDERSON, R. E.; TATHAM, R. L.; BLACK, W. C. Análise multivariada de dados. 5 ed. Porto Alegre: Bookman, 2005.

HANKINSON, G. Relational network brands: towards a conceptual model of place brands. Journal of Vacation Marketing, v. 10, n. 2, p. $109-121,2004$.

HANKINSON, G. The management of destination brands: five guiding principles based on recent developments in corporate branding theory. Brand Management, v. 14, n. 3, p. 240 - 254, 2007.

HANNA, S. ROWLEY, J. An analysis of terminology use in place branding. Place Branding and Public Diplomacy, v. 4, n. 1, p. 61 - 75, 2008.

HANSEN, R. H. The narrative nature of place branding. Place Branding and Public Diplomacy, v. 6, n. 4, p. $268-279,2010$.

HILL, R. P.; MARTIN, K. D. Broadening the paradigm of marketing as exchange: a public policy and marketing perspective. Journal of Public Policy and Marketing, v. 33, n. 1, p. 17-33, 2014.

HORELLI, L. Environmental human-friendliness as a contextual determinant for quality of life. Revue Européenne de Psychologie Appliquée, v. 56, p. 15 - 22, 2006.

INSCH, A.; FLOREK, M. A great place to live, work and play: conceptualizing place satisfaction in the case of a city's residents. Journal of Place Management and Development, v. 1. n. 2, p. 138-149, 2008.

INSCH, A. Managing residents' satisfaction with city life: application of importance-satisfaction analysis. Journal of Town and city management, v. 1. n. 2, p. 164-174, 2010.

JAMAL, T.; CAMARGO, B. A. Sustainable tourism, justice and an ethic of care: Toward the just destination. Journal of Sustainable Tourism, v. 22, n. 1, p. 11-30, 2013.

JONES, C. Major events, networks and regional development. Regional Studies, v. 29, n. 2, p. 185 195, 2005.

KAVARATZIS, M. From city marketing to city branding: towards a theoretical framework for developing city brands. Place Branding, v. 1, n. 1, p. 58 - 73, 2004.

KAVARATZIS, M.; ASWORTH, G. City branding: an effective assertion of identity or a transitory marketing trick? Tijdschrift voor Economische en Sociale Geografie, v. 96, n. 5, p. 506 - 514, 2005.

KILBOURNE, W. E.; CARLSON, L. The dominant social paradigm, consumption, and environmental attitudes: can macromarketing education help?. Journal of Macromarketing, v. 28, n. 2, p. 106-121, 2008.

KOTLER, P.; HAIDER, D. H.; REIN, I. Marketing places: attracting investment, industry, and tourism to cities, states, and nations. New York: The Free Press, 1993. 
KOTLER, P. GERTNER, D. Country as brand, product, and beyond: a place marketing and brand management perspective. Brand Management, v. 9, n. 4, p. 249 - 261, 2002.

KOTLER, P.; KELLER, K. L. Administração de marketing. São Paulo, Pearson Prentice Hall, 2006. LATTIN, J; CARROL, J. D.; GREEN, P. E. Análise de dados multivariados. São Paulo: Cengage Learning, 2011.

LAYTON, R. A. Marketing systems-a core macromarketing concept. Journal of Macromarketing, v. 27, n. 3, p. 227-242, 2007.

LAYTON, R. A. On economic growth, marketing systems, and the quality of life. Journal of Macromarketing, v. 29, n. 4, p. 349-362, 2009.

LAYTON, R. A. Towards a theory of marketing systems. European journal of marketing, v. 45, n. 1/2, p. 259-276, 2011.

LEE, D. J.; SIRGY, M. J. Quality-of-life (QOL) marketing: proposed antecedents and consequences. Journal of Macromarketing, v. 24, n. 1, p. 44-58, 2004.

LEE, M. S. W.; CHERRIER, H.; BELK, R. Journal of Macromarketing Special Issue: AntiConsumption Research and Society. Journal of Macromarketing, p. 0276146713485964, 2013.

MAI, N. T. T.; RAHTZ, D. R.; SHULTZ, C. J. Tourism as Catalyst for Quality of Life in Transitioning Subsistence Marketplaces: Perspectives from Ha Long, Vietnam. Journal of Macromarketing, p. 0276146713507281, 2013.

MAK, A. K. Y. An identity-centered approach to place branding: Case of industry partners' evaluation of Iowa's destination image. Journal of Brand Management, v. 18, p. 438 - 450, 2010.

MORANTA, T. V.; URRÚTIA, E. P. La apropiación del espacio: una propuesta teórica para comprender la vinculación entre las personas y los lugares. Anuario de Psicología, v. 36, n. 3, p. 281297, 2005.

MOSER, G. Quality of life and sustainability: toward person-environment congruity. Journal of Environmental Psychology, v. 29, p. 351 - 357, 2009.

OVIEDO-GARCIA, M.; CASTELLANOS-VERDUGO, M.; MARTIN-RUIZ, D. Gaining residents' support for tourism and planning. International Journal of Tourism Research, v. 10, n. 2, p. 95-109, 2008.

PAPADOPOULOS, N. Place branding: Evolution, meaning and implications. Place Branding, v. 1, n. 1, p. $36-49,2004$.

RAINISTO, S. K. et al. Success factors of place marketing: A study of place marketing practices in Northern Europe and the United States. Helsinki University of Technology, 2003.

RAYMOND, C. M.; BROWN, G.; WEBER, D. The measurement of place attachment: personal, community, and environmental connections. Journal of Environmental Psychology, v. 30, p. 422 434, 2010.

ROGERSON, R. J. Quality of life and city competitiveness. Urban Studies, v. 36, p. 969 - 985, 1999.

ROLLERO, C.; PICCOLI, N. Does place attachment affect social well-being? Revue Européenne de Psychologie Appliquée, v. 60, p. 233-238, 2010.

WALKER, A. J.; RYAN, R. L. Place attachment and landscape preservation in rural New England: a Maine case study. Landscape and Urban Planning, v. 86, p. 141 - 152, 2008.

WARNABY, G.; BENNISON, D.; DAVIES, B. J. Marketing town centres: retailing and town centre management. Local Economy, v. 20, n. 2, p. 183 - 204, 2005. 
WILKIE, W. L.; MOORE, E. S. Marketing's contributions to society. Journal of Marketing, v. 63, p. 198-218, 1999.

ZENKER, S. Who's your target? The creative class as a target group for place branding. Journal of Place Management and Development, v. 2, n. 1, p. 23 - 32, 2009.

ZENKER, S. How to catch a city? The concept and measurement of place brands. Journal of Place Management and Development, v. 4, n. 1, p. $40-52,2011$.

ZENKER, S.; PETERSEN, S.; AHOLT, A. The citizen satisfaction index (CSI): evidence for a four basic factor model in a German sample. Cities, 2012.

ZENKER, S.; RÜTTER, N. Is satisfaction the key? The role of citizen satisfaction, place attachment and place brand attitude on positive citizenship behavior. Cities, v. 38, p. 11-17, 2014.

\section{Recebido em: 23/03/2015 (1 ${ }^{\text {a }}$ versão) $23 / 09 / 2015$ ( $2^{\text {a }}$ versão)}

\section{Aprovado em: 20/10/2015}

\section{Apêndice - Medidas das variáveis dos construtos}

\begin{tabular}{|c|c|c|c|c|}
\hline Variáveis & Média & Mediana & Desvio & Escore \\
\hline \multicolumn{5}{|l|}{ Qualidade de vida percebida } \\
\hline Em geral minha vida está próxima do ideal & 6,26 & 7,00 & 2,44 & 0,748 \\
\hline Eu já alcancei as coisas que considero importantes na vida & 5,18 & 5,00 & 2,70 & 0,711 \\
\hline Eu estou satisfeito com minha vida & 7,00 & 7,00 & 2,26 & 0,830 \\
\hline $\begin{array}{l}\text { Se eu pudesse viver minha vida novamente, eu não mudaria } \\
\text { quase nada }\end{array}$ & 6,21 & 7,00 & 2,82 & 0,741 \\
\hline As minhas condições de vida são excelentes & 6,43 & 7,00 & 2,39 & 0,791 \\
\hline \multicolumn{5}{|l|}{ Apego (identidade) } \\
\hline A cidade onde moro é muito especial para mim & 7,36 & 8,00 & 2,66 & 0,831 \\
\hline Eu sinto como se a cidade onde moro fosse parte de mim & 6,30 & 7,00 & 2,97 & 0,884 \\
\hline Eu tenho memórias muito boas da cidade onde resido & 7,30 & 8,00 & 2,49 & 0,759 \\
\hline A cidade onde habito significa muito para mim & 7,07 & 7,00 & 5,78 & 0,561 \\
\hline Eu me identifico fortemente com a cidade onde habito & 6,56 & 7,00 & 2,85 & 0,878 \\
\hline Eu sou muito apegado à cidade onde moro & 6,12 & 6,00 & 2,94 & 0,879 \\
\hline $\begin{array}{l}\text { Viver na cidade onde moro representa uma grande parte do } \\
\text { que sou }\end{array}$ & 6,17 & 7,00 & 2,93 & 0,883 \\
\hline \multicolumn{5}{|l|}{ Apego (dependência) } \\
\hline $\begin{array}{l}\text { Eu tenho mais satisfação em morar onde moro do que teria } \\
\text { em qualquer outro lugar }\end{array}$ & 6,36 & 7,00 & 3,09 & 0,826 \\
\hline $\begin{array}{l}\text { Nenhum lugar seria melhor para o que faço do que a cidade } \\
\text { onde moro }\end{array}$ & 4,84 & 5,00 & 2,91 & 0,839 \\
\hline $\begin{array}{l}\text { Realizar minhas atividades na cidade onde moro é mais } \\
\text { importante para mim do que realizar as mesmas atividades } \\
\text { em outro lugar }\end{array}$ & 5,74 & 6,00 & 3,05 & 0,868 \\
\hline Nenhum lugar se compara à cidade onde habito & 5,20 & 5,00 & 2,96 & 0,863 \\
\hline A cidade onde habito é o melhor lugar para fazer o que gosto & 5,47 & 6,00 & 2,92 & 0,860 \\
\hline \multicolumn{5}{|l|}{ Satisfação geral com a cidade } \\
\hline O que tem na cidade onde resido é exatamente o & 5,61 & 6,00 & 2,48 & 0,778 \\
\hline $\begin{array}{l}\text { Eu estou satisfeito com o que tenho à disposição na cidade } \\
\text { onde moro }\end{array}$ & 5,79 & 6,00 & 2,66 & 0,880 \\
\hline $\begin{array}{l}\text { Minha experiência com o que tenho na cidade onde resido é } \\
\text { satisfatória }\end{array}$ & 6,06 & 6,00 & 2,49 & 0,816 \\
\hline Eu acredito que a cidade onde vivo me fornece bons serviços & 5,41 & 5,00 & 2,67 & 0,815 \\
\hline
\end{tabular}

